\title{
ASPECTOS EPIDEMIOLÓGICOS DA FEBRE MACULOSA NO BRASIL NOS \\ ÚLTIMOS CINCO ANOS DE NOTIFICAÇÃO
}

\author{
Ana Paula da Conceição Fernandes de Amorim¹; Juliana Ferreira de Amorim² \\ 1. Médica Veterinária. Universidade Federal do Rio de Janeiro (UFRJ), Rio de Janeiro, RJ, Brasil. \\ 2. Graduanda. Universidade Federal do Estado do Rio de Janeiro (UNIRIO). Rio de Janeiro - RJ, \\ Brasil.
}

DOI: $10.47094 /$ ICONRES.2021/19

\begin{abstract}
RESUMO
A febre maculosa é uma zoonose emergente de notificação compulsória e importância em saúde pública, causada pela bactéria $R$. rickettsii e transmitida por carrapatos. A bactéria já foi isolada em cavalos, gambás, capivaras, muares, cães domésticos e humanos. Há relatos de casos em áreas rurais e urbanas. Esse estudo transversal apresenta dados epidemiológicos da doença, notificados no Brasil nos últimos cinco anos, de 2013 a 2017, em banco de dados do DATASUS/Ministério da Saúde, mostrando a dispersão da doença e a população afetada. O estudo mostrou 833 casos notificados nesse período cujos homens foram os que mais sofreram o agravo. A maioria dos afetados em idade produtiva evoluiu para a cura embora o número de óbitos também tenha sido expressivo. As notificações mostraram que a maioria dos casos ocorreu nas áreas urbanas da região sudeste e o estado de São Paulo foi o que apresentou maior numero de casos.
\end{abstract}

PALAVRAS-CHAVES: Doença do carrapato; Riquetsiose; Zoonose emergente.

ÁREA TEMÁTICA: Saúde Coletiva

\section{INTRODUÇÃO}

A febre maculosa (FM) é uma zoonose, de caráter endêmico emergente transmitida pela bactéria $R$. rickettsii, principalmente, com a participação de carrapatos vetores (Ueno et.al. 2020; Nunes et. al, 2020; Campos et.al. 2020; Martins, et.al., 2016). Foi identificada em 1896, no Vale do Rio Snake, Idaho, EUA, e atualmente é notificada em quase todos os estados norteamericanos. A partir de 1930, a doença foi identificada também em outros países como Canadá, México, Costa Rica, Panamá, Colômbia, Brasil e Argentina. No Brasil, a FM foi identificada em 1929 
(Martins, et.al., 2016). Hoje já se aceita a possibilidade de a FM ser transmitida por outros gêneros de Riquétsias infecciosas, conforme determinado a partir de diferenças de títulos de anticorpos contra diferentes antígenos de Rickettsia, como a R. parkeri ou R. bellii . (Uono, et.al.2020)

Os carrapatos, vetores envolvidos na transmissão da FM são ectoparasitas de distribuição mundial que afetam vertebrados e podem transmitir patógenos a diversos animais e humanos (Gonzalesz et.al.2017). Estudos demonstraram que embora o carrapato do gênero Amblyomma, como o A. aureolatum, presente em animais silvestres, e A. cajennense, carrapato estrela ou do cavalo, reconhecido como principal vetor (Martins, et.al., 2016). Estudo recentes correlacionaram outros gêneros envolvidos na transmissão da Rickettsia sp mostram que os carrapatos vetores mais encontrados em estudos a campo foram o Amblyomma sculptum, cujos os principais hospedeiros são os eqüinos, gambás, capivaras e antas (Ueno et.al. 2020); o Amblyomm dubitatum, cujos hospedeiros mais comuns são as capivaras (Nunes et.al. 2020) e Rhipicephalus sanguineus, muito frequente em cães domésticos, que tem um importante papel como sentinelas da doença (Campos, et, al, 2020).

É uma doença de notificação compulsória de grande importância em saúde pública, tanto no âmbito da medicina humana quanto na medicina veterinária e atualmente há relatos de casos em áreas rurais e urbanas (Ueno, et.al. 2020; Nunes, et.al, 2020; Campos, et.al. 2020).

O objetivo deste estudo é apresentar dados no Ministério da Saúde sobre a febre maculosa notificados entre os anos de 2013 a 2017, dados esses que foram atualizados em 2019.

\section{METODOLOGIA}

Esse trabalho é um estudo transversal, quantitativo e retrospectivo, em banco de dados do Ministério da Saúde/SVS - Sistema de Informação de Agravos de Notificação - SinanNet (DATASUSSINAN), sobre febre maculosa notificadas no Brasil no período de cinco anos entre 2013 e 2017. Os dados foram atualizados em 29/01/2019, totalizando 833 casos notificados nesse período. Os indicadores usados foram: unidades da federação, através da notificação compulsória do agravo; gênero; idade; evolução do caso e região de ocorrência. Para análise estatística descritiva simples foi utilizado o software Excel 2007.

A revisão bibliográfica levou em conta as palavras chave e o tema principal sobre febre maculosa, pesquisadas nas plataformas PubMed, Scielo e BVS. Na escolha dos artigos optou-se por artigos publicados nos últimos cinco anos e que tivessem como foco a multiplicidade de animais sujeitos à infecção e também o homem. 


\section{RESULTADOS E DISCUSSÕES}

O Brasil notificou entre os anos de 2013 a 2017 (dados atualizados em 17/01/2018), 833 casos de febre maculosa. O Sudeste foi a região que apresentou maior ocorrência com $72,15 \%$ dos casos sendo que apenas o estado de São Paulo teve 65,06\% do total da região Sudeste. As outras regiões tiveram respectivamente e em ordem de numérica de ocorrências: Sul (22,93\%), Nordeste (2,40\%); Centro-Oeste (1,92\%) e Norte ( $0,60 \%)$. Além de São Paulo os estados que mais notificaram a doença nesse período foram: Goiás (50,00\%), Santa Catarina $(83,77 \%)$, Ceará $(90,00 \%)$ e no Norte do país apenas o estado de Rondônia notificou (100\%) dos casos. Os anos de maior notificação foram 2015 e 2017 ambos igualmente com 21,10\% dos casos. O de menor ocorrência notificada foi 2013 com $15,58 \%$. A população afetada foi principalmente do sexo masculino com $72,51 \%$ das notificações e a idade mais afetada foi entre 20 e 59 anos perfazendo $63,03 \%$ do total dos casos. O que representa um importante impacto na faixa etária produtiva.

Quanto à evolução 38\% dos casos evoluiu com óbito do paciente e esse dado foi acompanhado pela região Sudeste e pelo estado de São Paulo que, além de ter o maior numero de notificações, teve também o maior numero de óbitos.

Já em relação à região de ocorrência registrada nas notificações, 72,75\% dos agravos ocorreram na área urbana. Todas as regiões brasileiras apresentaram a área urbana como a principal área de localização dos casos notificados.

\section{CONCLUSÃO}

A febre maculosa é uma doença emergente de importância em saúde pública e potencialmente patogênica para os seres humanos e vem ocorrendo mais frequentemente em regiões urbanas. Essa situação pode ser atribuída ao fato de que os patógenos de Rickettsia circulam em cães, que convivem muito bem com humanos e que inclusive podem servir como sentinelas de rickettsioses no ambiente urbano, e de diversos animais inclusive silvestres, antropizados, nas zonas urbanas. Outro fator é a presença constante de carrapatos em ambientes fechados, domiciliares ou peridomiciliares. Essa condição pode constituir um novo perfil de Riquetsioses distinto do rural, onde tradicionalmente ocorre a FM.

Evitar picadas de carrapatos é a única forma de prevenção disponível da doença. Uso de roupas de proteção e repelentes contra carrapatos, inspeção do corpo uma ou duas vezes ao dia e remoção de carrapatos antes de inocularem Rickettsia, reduzem o risco de infecção em ambientes rurais. Em ambientes urbanos, deve-se evitar aproximação e manipulação de animais silvestres, e controle rigoroso de ectoparasitos em cães e gatos domésticos, com visitas frequentes ao veterinário. Controle populacional de espécies como capivaras, por exemplo, em áreas com risco de transmissão de FM, é fundamental e pode diminuir a necessidade de eutanásia desses animais, principalmente nas situações em que eles possam freqüentar áreas urbanas ou periurbanas. 


\section{REFERÊNCIAS}

CAMPOS, S. D. E.; CUNHA, N. C. da; MACHADO, C. de S. C.; TELLERIA, E. Z.; CORDEIRO, M. D.; FONSECA, A. H. da; TOMA, H. K.; SANTOS, J. P. C. dos; ALMOSNY, N. R. P. Rickettsial pathogens circulating in urban districts of Rio de Janeiro, without report of human Brazilian Spotted Fever. Revista Brasileira de Parasitologia Veterinária, 29(4): e014220, 2020. 1-10P. Disponível em: https://www.scielo.br/pdf/rbpv/v29n4/1984-2961-rbpv-29-4-e014220.pdf. Acesso em 23/02/2021.

GONZALEZ, I. H. L; LABRUNA, M. B; CHAGAS, C. R. F.; SALGADO, P. A. B.; MONTICELLI, C.; MORAIS, L. H.; MORAES, A. A. de; ANTUNES, T. C.; RAMOS, P. L.; MARTINS, T. F. Ticks infesting captive and free-roaming wild animal species at the São Paulo Zoo, São Paulo, Brazil. Braz. J. Vet. Parasitol. Jaboticabal, v. 26, n. 4, p. 496-499, oct.-dec. 2017. Disponível em:https://www. scielo.br/pdf/rbpv/v26n4/1984-2961-rbpv-S1984-29612017036.pdf. Acesso em 24/02/2021.

NUNES, F.B. P.; NUNES, A. Z.; NUNES, M. P.; LABRUNA, M.B.; PIZZUTTO, C. S. Reproductive control of capybaras through sterilization in areas at risk of transmission of brazilian spotted fever. Ciência Rural. Santa Maria, v.50:9, e20200053, 2020. 1-9p. Disponível em: https:/www.scielo.br/ pdf/cr/v50n9/1678-4596-cr-50-09-e20200053.pdf. Acesso em 23/02/2021.

UENO, T. E. H.; CUTOlO, A. A.; MARTINS, T. F. ; MORAES-FILHO, J.; AZEVEDO, S. S. de; LABRUNA, M. B. Rickettsial infection in equids, opossums and ticks in the municipality of Monte Mor, state of São Paulo, Brazil. Revista Brasileira de Parasitologia Veterinária, vol.29, n.4, e015420. Epub Nov 23, 2020. 1-9p. Disponível em: https://www.scielo.br/pdf/rbpv/v29n4/19842961-rbpv-29-4-e015420.pdf. Acesso em 24/02/2021.

MARTINS, M.E.P.; BRITO, W.M.E. D.; LABRUNA, M.B; FILHO, J. M.; SOUSA-MARTINS, K. C.; RAFAEL PORTO VIEIRA, R. P. Epidemiological survey of supposed spottedfever outbreak. Ciência Animal Brasileira v.17, n.3, p. 459-471 jul./set. 2016. Disponível em: https://www.scielo. br/pdf/rbpv/v26n4/1984-2961-rbpv-S1984-29612017036.pdf. Acesso em 24/02/2021. 